\begin{tabular}{|c|c|}
\hline Date: & May 2015 \\
\hline Description: & $\begin{array}{l}\text { Overview on thermal loads on components of standard flat-plate collectors in an } \\
\text { one year lasting field-test as a basis for overheating protection and material } \\
\text { selection for polymeric collector development }\end{array}$ \\
\hline Author: & Dipl.-Ing. (FH) Christoph Reiter; christoph.reiter@thi.de \\
\hline Co-author(s): & $\begin{array}{l}\text { Dr. Sebastian Brandmayr, Dr. Christoph Trinkl, Prof. Dr.-Ing. Wilfried Zörner } \\
\text { Technische Hochschule Ingolstadt } \\
\text { Institute of new Energy Systems (InES) }\end{array}$ \\
\hline Available languages: & English \\
\hline Download at: & http://task39.iea-shc.org/ \\
\hline
\end{tabular}

\title{
Introduction
}

Apart from the maximum absorber temperature according to DIN EN ISO 9806 (2014), the thermal loads inside solar-thermal collectors are widely unknown. However, the use of cost-effective polymers requires a detailed knowledge about the thermal conditions the collector components are facing. Therefore, a conventional solar-thermal system integrated in a four person one-family house was analyzed in a fieldtesting (cf. Reiter et al. 2010). The house was equipped with a solar hot water and space heating system with $20 \mathrm{~m}^{2}$ of standard flat-plate collectors. The measurement data were analyzed in detail regarding the following aspects:

- Maximum temperatures at the collector components

- Dynamic behavior of thermal loads

- Accumulated temperature exposition times

The latter are an essential basis for polymeric material selection and development, a prediction of material property changes over the expected life time and an adoption of solar-thermal systems and collector design to polymer requirements.

\section{Measurement Equipment}

Measurement equipment was applied to both the system and one collector in order to specify the thermal and pressure loads on the collector at casing, absorber, glazing and insulation in detail. Furthermore, a dry collector without connection to the solar-thermal system was installed to refer to maximum loads during continuous stagnation. Table 1 shows the parameters of the investigated collectors. 


\begin{tabular}{|lccc|}
\hline Parameter & Symbol & Value & Unit \\
\hline Optical efficiency & $\eta_{0}$ & 0.798 & - \\
Linear heat loss coefficient & $\mathrm{a}_{1}$ & 3.34 & $\mathrm{~W} /\left(\mathrm{m}^{2} \mathrm{~K}\right)$ \\
Quadratic heat loss coefficient & $\mathrm{a}_{2}$ & 0.0075 & $\mathrm{~W} /\left(\mathrm{m}^{2} \mathrm{~K}^{2}\right)$ \\
Heat capacity of the collector & $\mathrm{C}$ & 9.5 & $\mathrm{~kJ} / \mathrm{K}$ \\
\hline
\end{tabular}

Table 1: Parameters of the investigated state-of-the-art collector

Figure shows a part of the tested collector array and exemplary temperature sensors applied at the frame of the collector. In Reiter et al. 2011 the measurement equipment and the sensor positions are described in detail.
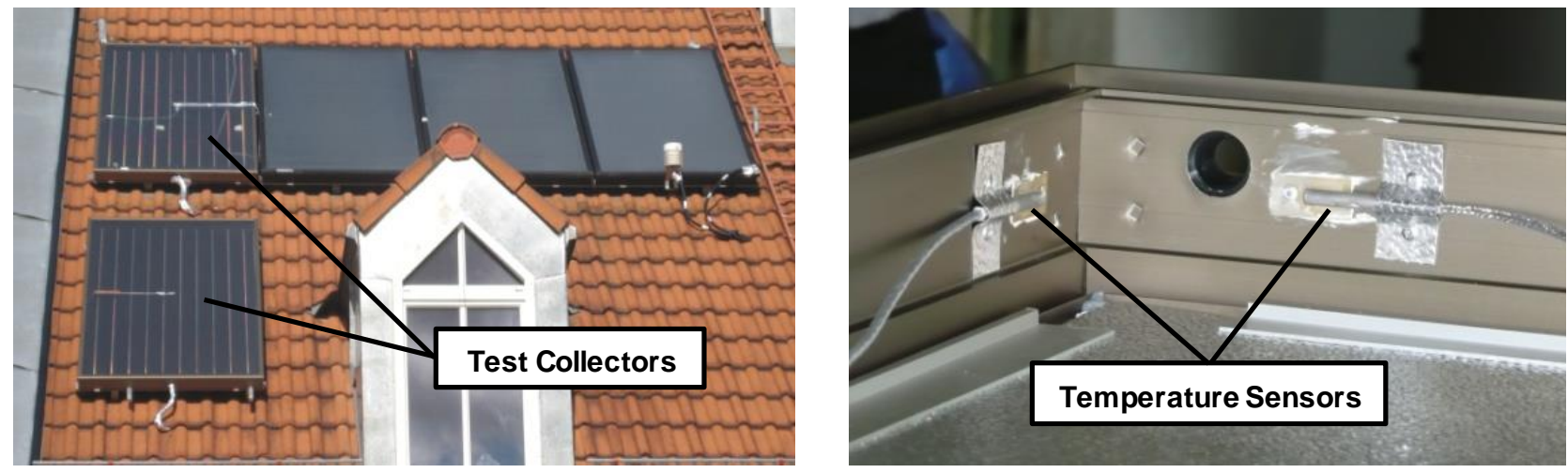

Figure 1: Field-testing of collectors (left) and exemplary temperature measurement equipment at a collector casing (right; Reiter et al. 2012)

\section{Annual Field Testing Results}

Measurement results for one year (Jan. 2009 to Dec.2009) are analyzed in histograms with a class width of 10K (Figure 1). In order to provide a more detailed overview of high temperatures periods, the vertical axis is limited to $500 \mathrm{~h}$, so that the comparably long durations at low temperatures, for example during the night, are not shown. Furthermore, it has to be considered, that technical problems with the data acquisition led to missing 10 measurement days in March and 19 days in June.

The absorber in the system reached temperatures up to $140^{\circ} \mathrm{C}$ while operating and during stagnation temperatures up to $192^{\circ} \mathrm{C}$. These high temperatures were measured at the upper part of the collector near the outlet. Despite the relatively large collector area, the solar thermal system was rarely in stagnation, as the radiators in the basement of the house were used to avoid stagnation by cooling the buffer storage.

To measure the hottest spot of the dry absorber the sensor was positioned in the center point of the component, where a maximum temperature of $208^{\circ} \mathrm{C}$ was recorded. During the measurement period shown in Figure 3, the absorber remained at more than 1,100h above a temperature level of $95^{\circ} \mathrm{C}$. 


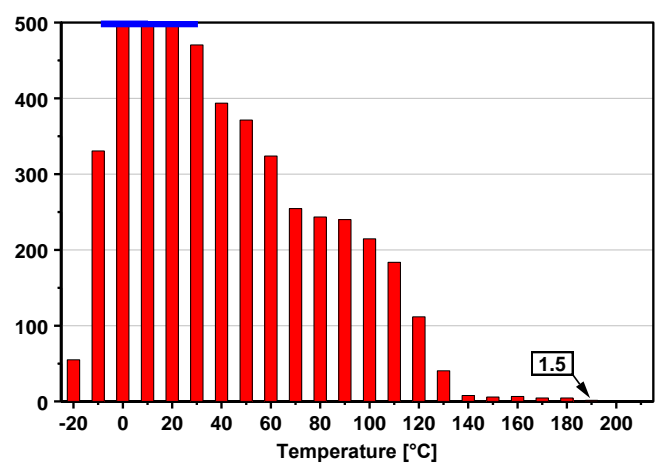

Figure 1: Temperature histogram of the absorber fin

(collector in the system; Reiter et al. 2012)

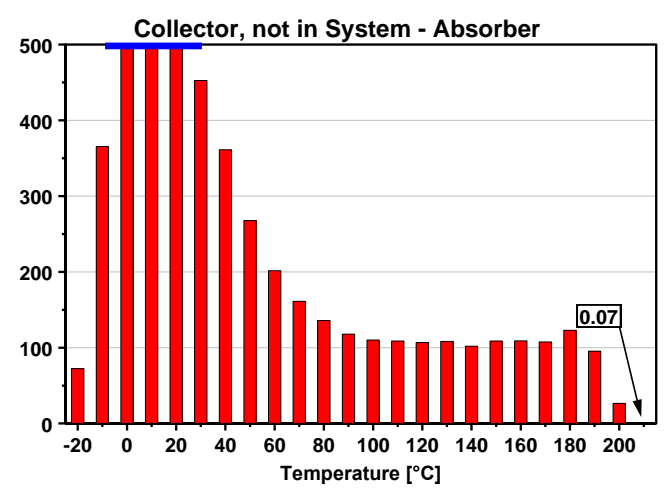

Figure 2: Temperature histogram of the absorber fin

(dry collector; Reiter et al. 2012)

The temperature of the transparent cover was measured with a shaded, bonded sensor at the inner surface in central position for both collectors. At the glazing of the collector in the system, temperatures above $55^{\circ} \mathrm{C}$ mainly occurred during the system stagnation (Figure 3). The maximum temperature was $82^{\circ} \mathrm{C}$. However, the temperature load is on an uncritical level for a wide variety of potential transparent cover sheet materials.

As was anticipated, the cover of the dry collector showed a significantly higher temperature level than the collector in operation (Figure 4). The surface temperature of this component was above $55^{\circ} \mathrm{C}$ for $585 \mathrm{~h}$ in the considered measurement period. The maximum temperature lay at $86^{\circ} \mathrm{C}$, also an uncritical level for most polymeric cover sheet materials.

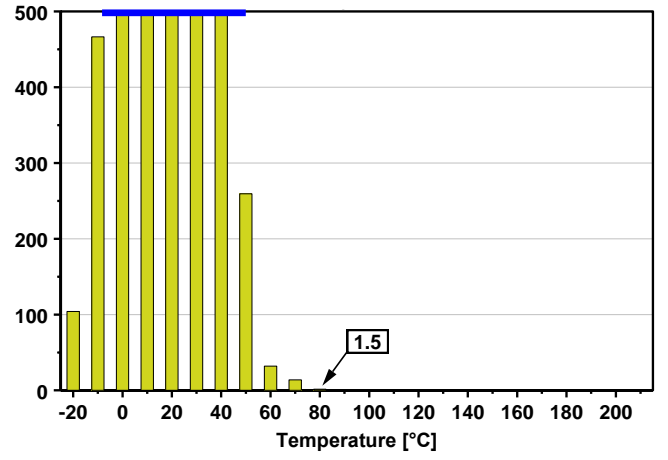

Figure 3: Temperature histogram of the glazing (collector in the system; Reiter et al. 2012)

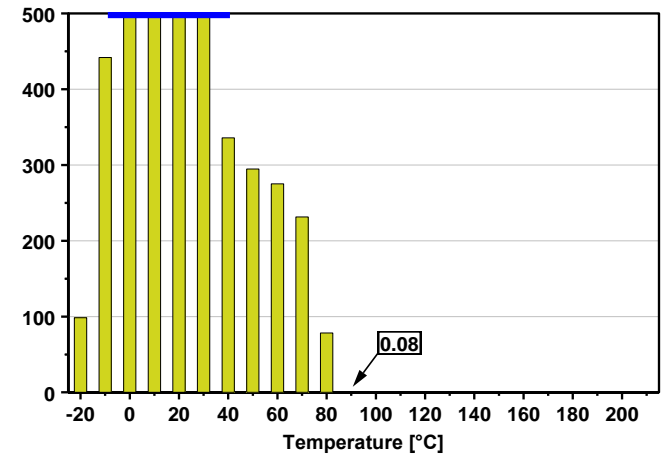

Figure 4: Temperature histogram of the glazing (dry collector; Reiter et al. 2012)

For the investigation of the frame temperatures, several sensors were positioned on the inner surface of the aluminum frame by rivets, outside the collector insulation. The sensor used for the analysis of the collector in the system was located at the upper side of the collector near the outlet (Figure ; right picture). The temperature sensor in the dry collector was positioned central at the upper part of the frame. 
The maximum temperatures of both collectors measured by these sensors were below $80^{\circ} \mathrm{C}$. The frames mostly reached temperatures below $65^{\circ} \mathrm{C}$. Figure 5 and Figure 6 show the limited thermal loads on the housings. Hence, the temperature of the casing already fulfills the thermal requirements of commodity plastics.

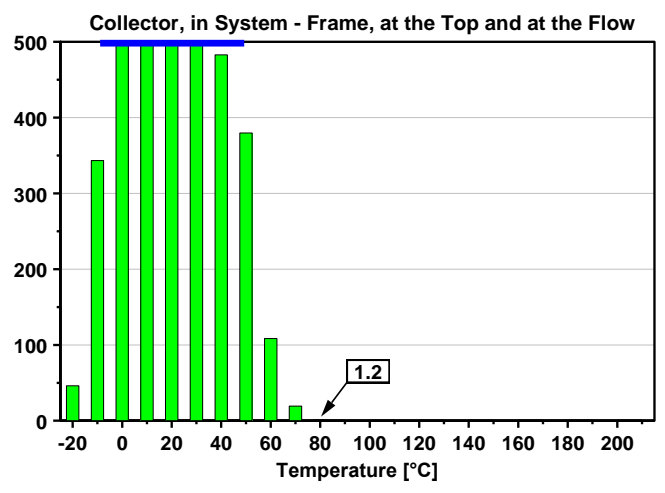

Figure 5: Temperature histogram of the frame (collector in the system; Reiter et al. 2012)

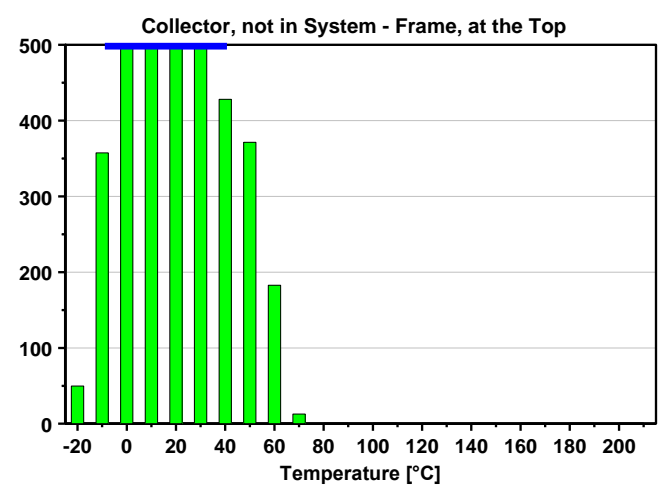

Figure 6: Temperature histogram of the frame (dry collector; Reiter et al. 2012)

\section{Detailed Field Testing Results}

Apart from the maximum collector temperature, the dynamic behavior of the components is of major interest. On the one hand, rapid temperature changes must be considered in the collector design, due to different linear thermal expansion of components and materials. On the other hand, the response time for temperature reducing measures in the solar-thermal system can therewith be estimated.

Figure 7 demonstrates the outstanding dynamic behavior of the dry absorber in comparison to the moderate response of the casing. The temperature of the absorber increased by 125K (09:30-10:45a.m.) and decreased by $121 \mathrm{~K}$ (10:45-12:00a.m.) in only 2.5hours. During cooling down, short sunshine periods between 11:00-11.30a.m. caused further significant rises of the absorber temperature. The temperature of the casing increased from $12^{\circ} \mathrm{C}$ up to only $35^{\circ} \mathrm{C}$, while the ambient air temperature was between $9^{\circ} \mathrm{C}$ and $14^{\circ} \mathrm{C}$. 


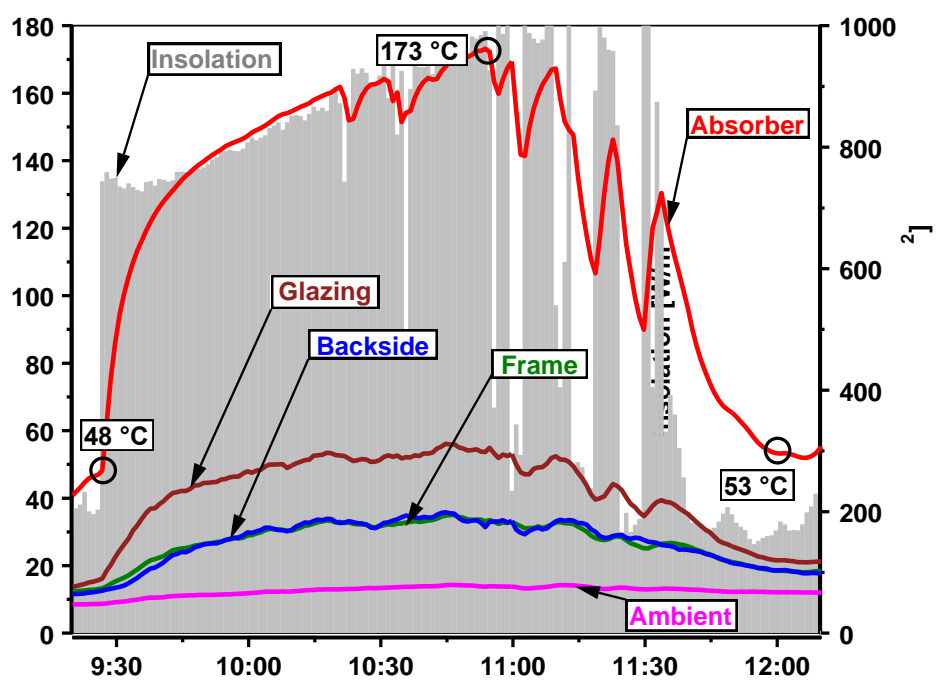

Figure 7: Temperature profile of the dry collector in September (Reiter et al. 2012)

There is also high absorber dynamics at ambient temperatures near to the freezing point in winter. The temperatures of the components of the dry collector were below $5^{\circ} \mathrm{C}(10: 45 \mathrm{a}$.m.). After the sky cleared, the absorber temperature increased by $140 \mathrm{~K}$ in 45 minutes whereas the glazing temperature increased only by $45 \mathrm{~K}$ (Figure 8 ). Especially at low ambient temperatures, there is a large difference between thermal behavior of the absorber and the housing, which have to be considered in the collector design.

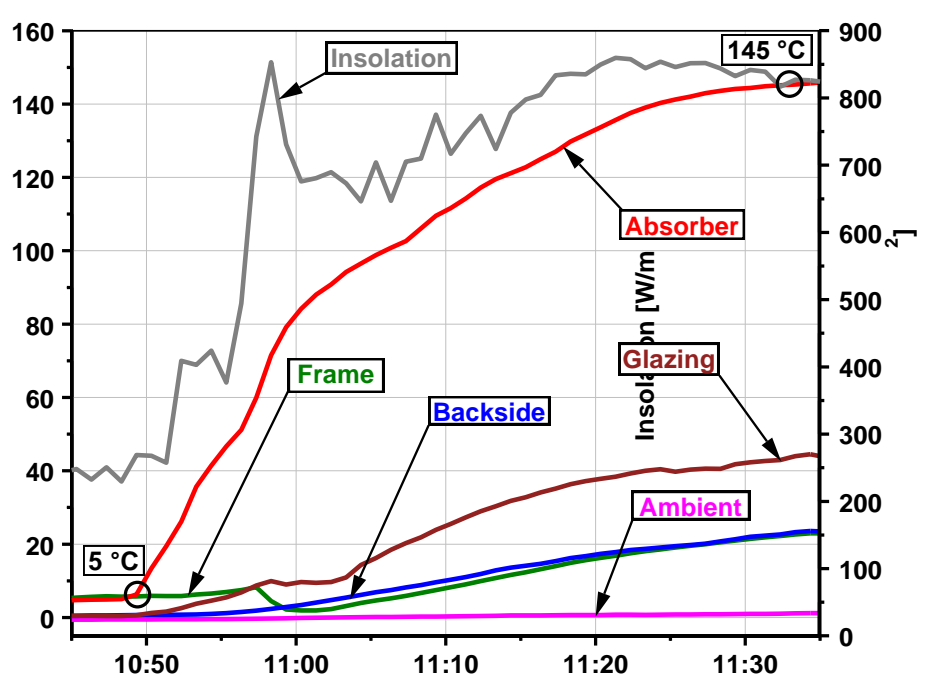

Figure 8: Temperature profile of the dry collector in winter (December) 


\section{O-OSTASK39 \\ Thermal loads at components of \\ state-of-the-art flat-plate collectors}

\section{Summary}

In summary, the field-testing measurements show that the specification for the material selection has to be based on the thermal loads of each single collector component. The common maximum absorber temperature from certification measurements is not an adequate approach for the determination of the thermal loads on the collector. The measured data from field testing clearly show that temperatures at the glazing and at the casing do not represent major obstacles for cost-effective polymers, even in highly efficient state-of-the-art collectors. The absorber and the insulation have to withstand remarkable thermal loads and are subject to considerable temperature fluctuations. Therefore, temperature limiting approaches and suitable component designs for polymeric collector development are needed.

\section{References}

DIN EN ISO 9806 (2014) Solar energy - Solar thermal collectors - Test methods (ISO 9806:2013); German version EN ISO 9806:2013. DIN German Institute for Standardization. Berlin (GER): Beuth Verlag GmbH, pp.16.

REITER, C. et al. (2010) Thermal Load Analysis of a Solar-Thermal Flat-Plate Collector in a Domestic Heating System. In: EUROSUN 2010 - International Conference on Solar Heating, Cooling and Buildings - Book of Abstracts, Graz (AT), September 2010. Graz: AEE INTEC, pp. 113.

REITER, C. and TRINKL, C. and ZÖRNER, W. (2011) Solarthermie2000plus: Kunststoffe in solarthermischen Kollektoren - Anforderungsdefinition, Konzeptentwicklung und Machbarkeits-bewertung. Final Report 0329285A for the Federal Ministry for the Environment, Nature Conservation and Nuclear Safety. Ingolstadt: Centre of Excellence for Renewable Energy Research, Ingolstadt University.

REITER, C. and TRINKL, C. and ZÖRNER, W. (2012) Thermal Loads on Solar Collectors and Options for their Reduction. In: KOEHL, M. et al. (eds.) Polymeric Materials for Solar Thermal Applications. $1^{\text {st }}$ ed. Weinheim(GER): Wiley-VCH Verlag GmbH \& Co. KGaA. 